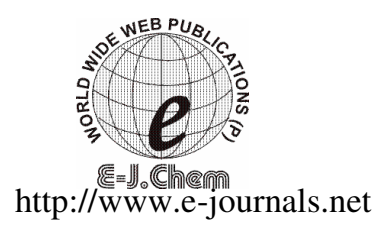

ISSN: 0973-4945; CODEN ECJHAO

E-Journal of Chemistry

2010, 7(S1), S127-S130

\title{
A New Cross-Shaped Graphite Furnace with Ballast Body for Reduction of Interferences in Atomic Absorption Spectrometry
}

\author{
A. A. ASWEISI ${ }^{*}$ and H-M KUSS \\ Faculty of Science, Garyounis University, Benghazi-Libya \\ asweisil@yahoo.com
}

Received 22 February 2010; Accepted 21 May 2010

\begin{abstract}
A new crossed graphite furnace for atomic absorption spectrometry (GFAAS) was designed and installed in heated graphite atomizer (HGA500) combined with Perkin-Elmer spectrometer (AAS1100). The Tungsten ballast body was inserted inside one part of the crossed furnace in a way perpendicular to light path. The analyzed sample was injected manually on the ballast body inside the cross and pushed into the measuring zone using the original inner and additional purge gas. The sample was adsorbed strongly on the ballast and evaporated and transferred with different rates at different temperatures during the temperature program allowing the separation of analyte and matrix signals. Analysis of middle volatile element such as copper and manganese in standard urine sample (seronorm 2525) showed complete separation of analyte and background signals with good sensitivity and repeatability.
\end{abstract}

Keywords: Graphite furnace, Spectral interferences, High temperature chromatography.

\section{Introduction}

Electrothermal atomizers are devices that are heated electrically in order to dissociate metal salts or compounds to free gaseous atoms of the metal for spectrometric measurements. During the last two decades many designs of electrothermal atomizers (ETA) have been created, the first commercial atomizers made by massman followed by graphite rods, metal strips, metal coils and graphite tubes ${ }^{1}$. The sample vaporization and degree depends on the heating procedure and the physical and chemical nature of the surface from which the being vaporized. The atomization degree depends on the effective temperature and on the chemical composition of the atomization zone. The analyte residence time is strongly affected by the geometrical structure of the tube, temperature distribution along the tube and flow rate of purge gas. The value and the shape of the absorption signals which in turn describes the sensitivity and reliability of the measurements depends also on the tube geometry. 
Reduction of interferences becomes possible with the separation of vaporization and atomization zones, the first separation was developed by L.vov, the sample was placed on graphite electrode and dried. Then the electrode is inserted inside the furnace for analysis. This method showed higher sensitivity and less interference. The smaller sample volume $(1.0 \mu \mathrm{L})$ led to higher relative standard deviation (RSD).

In order to eliminate these drawbacks, the atomizers began to develop in the direction of complete separation of vaporization and atomization zones. One successful solution was the appearance of graphite furnaces with different ballast bodies and half separated vaporization and atomization zones such as L,vov platform and Katskov atomizer ${ }^{2}$. The atomizers with these ballast bodies help to solve some analytical problems. The shape and the size of the ballast body are limited by the size of the graphite tube used because the ballast body must not block the light beam. A new design for separation of vaporization and atomization was created by many authors ${ }^{3-6}$ known as two-step atomizers. These systems were composed of a cup-vaporizer and tube atomizer and both are heated separately by two power units. The two-step atomizers are good for solid sample analysis and chemical interference reduction, but these atomizers were of very complex design and the transfer of analyte from vaporizer to atomizer only by normal diffusion.

Another two-step atomizer with purge gas was designed by Grinshtein ${ }^{6}$. With this system the vaporizer and atomizer are heated independently and sample (20-100 $\mu \mathrm{L})$ was injected, dried and transferred from vaporizer to atomizer with the help of purge gas. This device provides better sensitivity and reduction of matrix interferences. Draw back of this system is also a complex design, not well protected and large distance between atomizer and vaporizer allow the escape of the sample out of the measuring zone ${ }^{7}$. The aim of this work is to investigate some analytical characteristics of the new crossed furnace design with ballast body.

\section{Experimental}

The crossed furnace atomizer used in this work (Figure $1 \& 2$ ) is made of non coated graphite (Ringsdorf-Germany) with purity of $99.9 \%$. The new furnace is installed in Perkin-Elmer 1100 spectrometer equipped with heated graphite atomizer (HGA500) and deuterium lamp as background corrector. This installation was possible after rotating of the main furnace house clockwise with $90^{\circ}$. The ballast body was made of pure tungsten and inserted manually inside the furnace, the standard urine sample (seronorm 2525) was then injected manually using eppendorf pipette. Argon of high purity type 4.5 was used as inner carrier gas, outer protective gas to provide a non reactive environment and to minimize the diffusion of oxygen gas to the furnace during the heating steps where the oxidation of graphite is possible.

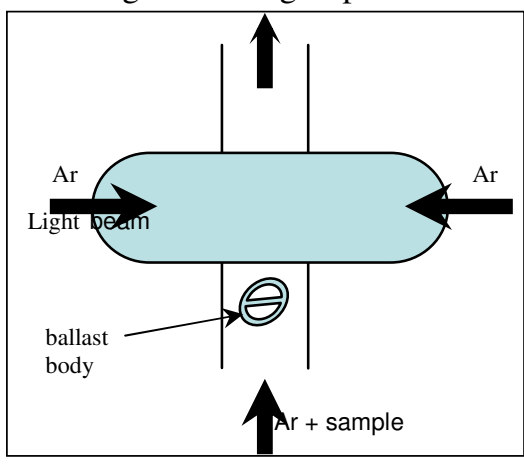

Figure 1. Schematic diagram for crossed furnace

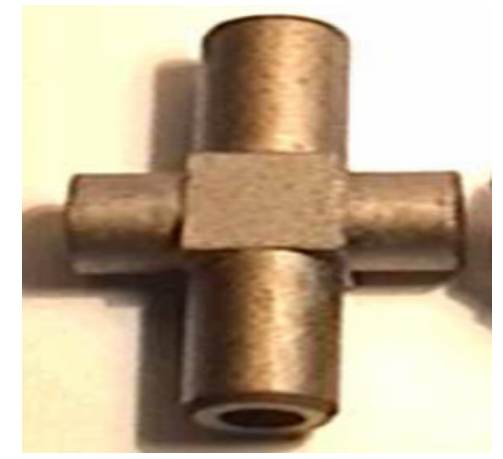

Figure 2. Real picture 
Hollow cathode lamp of varian type was used with lamp current of $5.0 \mathrm{~mA}$. Normal tap water was used as cooling system during the analysis.

\section{Results and Discussion}

Trace element analysis in standard urine sample using the new crossed furnace design with tungsten ballast for middle volatile elements such as copper and manganese are shown in Figures $3 \& 4$. The new design with high temperature chromatography principle and continuous argon flow measurements allows the complete separation of analyte and background signals in both cases. The analyzed sample is adsorbed strongly on the tungsten ballast surface, then atomized and transferred into the measuring zone with the aid of argon gas in different rates. Since manganese is more volatile than copper, it needs lower atomization temperature for the measurement and the manganese signals are sharper than that with copper and returns to the base line at time less than three seconds as can be seen in Figure 3.

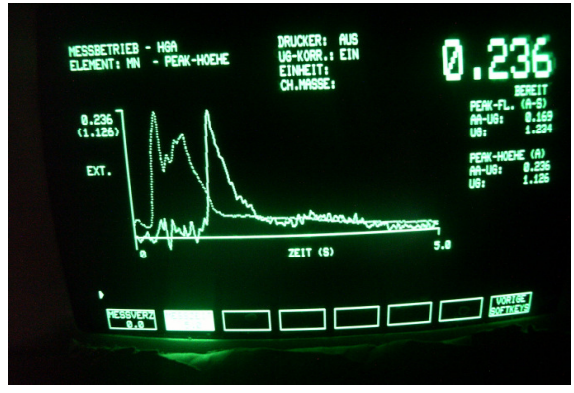

Figure 3. Mn and background signals

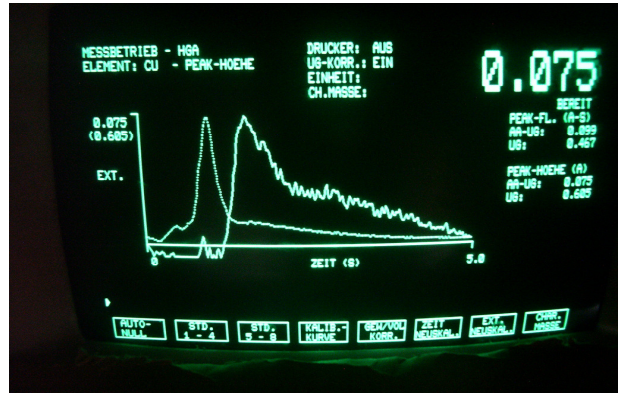

Figure 4. $\mathrm{Cu}$ and background signals

With peak height mode analysis of manganese in non diluted standard urine sample showed absorbance of $0.236 \mathrm{~A}$ and background absorbance of 1.126A, which is about five times higher than that for manganese. Such difference between analyte and background signals is not accepted using the deuterium lamp background correction if both signals are super imposable on each other which is the usual case using all the conventional AAS systems. The absorbance values are accepted with the new design because of analyte and matrix signals separation. The short time temperature program was used for this determination, 10-10 seconds (ramp-hold) time for drying step at $120{ }^{\circ} \mathrm{C}$ then 5 seconds (hold) and fast heating rate for atomization step at $2300{ }^{\circ} \mathrm{C}$, no pyrolysis steps were used during this analysis. This leads to determination of elements with less analyte loss during the pyrolysis step used with the conventional AAS systems. The argon flow rate during the drying step was $500 \mathrm{~mL} \mathrm{~min}^{-1}$, and then the flow rate reduced to $40 \mathrm{~mL} \mathrm{~min}^{-1}$ with laminar flow to allow the transfer of the sample composition gradually to the measuring zone depending on the adsorption power difference of the tungsten ballast.

In case of copper, the same argon flow rates were used during the drying and atomization steps and atomization temperature of $2500{ }^{\circ} \mathrm{C}$ was used. The analysis showed analyte signal of $0.075 \mathrm{~A}$ and background signal of $1.60 \mathrm{~A}$. A very high background signal as compared to the analyte signal, such analysis is also impossible with all AAS systems, but this analysis is possible using the new crossed furnace design with complete separation of analyte and matrix signals. The background signal in case of manganese is wider than that with copper because of higher atomization temperature was used in the second case. In addition to the less volatility of copper as compared to manganese, copper can form more stable carbides with the non coated graphite material which in turn requires both higher temperatures and longer time for breaking these bonds. This can be indicated by broad peak of about 3.5 seconds for copper as compared with that for manganese with peak of about 1.5 second. 


\section{Conclusion}

Analysis of highly interfering matrix such as urine could be done without pretreatment or dilution using the new crossed furnace design with continuous flow mode based on high temperature chromatography principle since it allows the separation of analyte and matrix signals. The short time temperature program saving time and increases the half life time of the graphite tube. The less volatile element and refractory elements can be easily analyzed since they evaporated at temperatures higher than that for copper. The sensitivity is comparable with that for conventional systems but the former requires pretreatment and sample dilution.

\section{References}

1. Docekal Bohumil, Spectrochimica Acta B., 1998, 53, 427-435.

2. Katskov D and Grinshtein I L, Abstract of the $18^{\text {th }}$ Congress on Spectroscopy, Gorki, Russia 1977, 147.

3. Frech W and Hadgu N, Spectrochimica Acta B., 2000, 55(5), 461-472.

4. $\quad$ Frech W, Baxter D C and Lundberg E, J Anal At Spectrom., 1988, 43B, 1115.

5. Grinshtein I L, Vilpan Y A, Saraev A V and Vasilieva L A, Spectrochimica Acta B, 2001, 56(3), 261.

6. L,Vov B, Atomic absorption spectrochemical analysis, Adam Hilger Ltd, London, 1970.

7. Kuss H M and Asweisi A A, Shimadzu News 3- (German), 2007. 


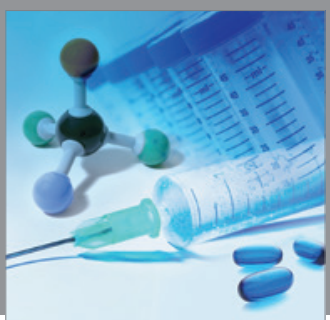

International Journal of

Medicinal Chemistry

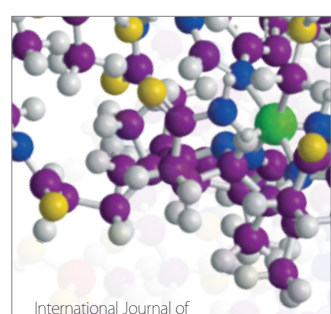

Carbohydrate Chemistry

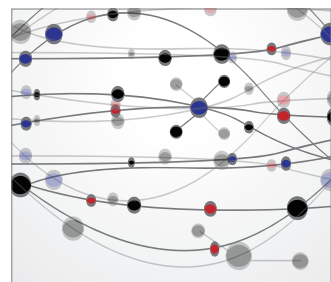

The Scientific World Journal
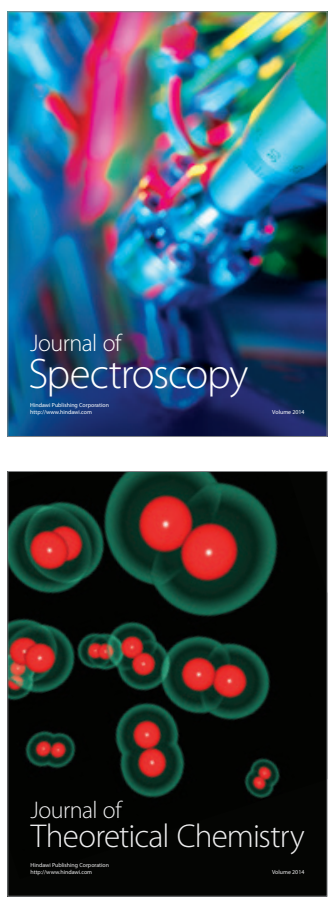
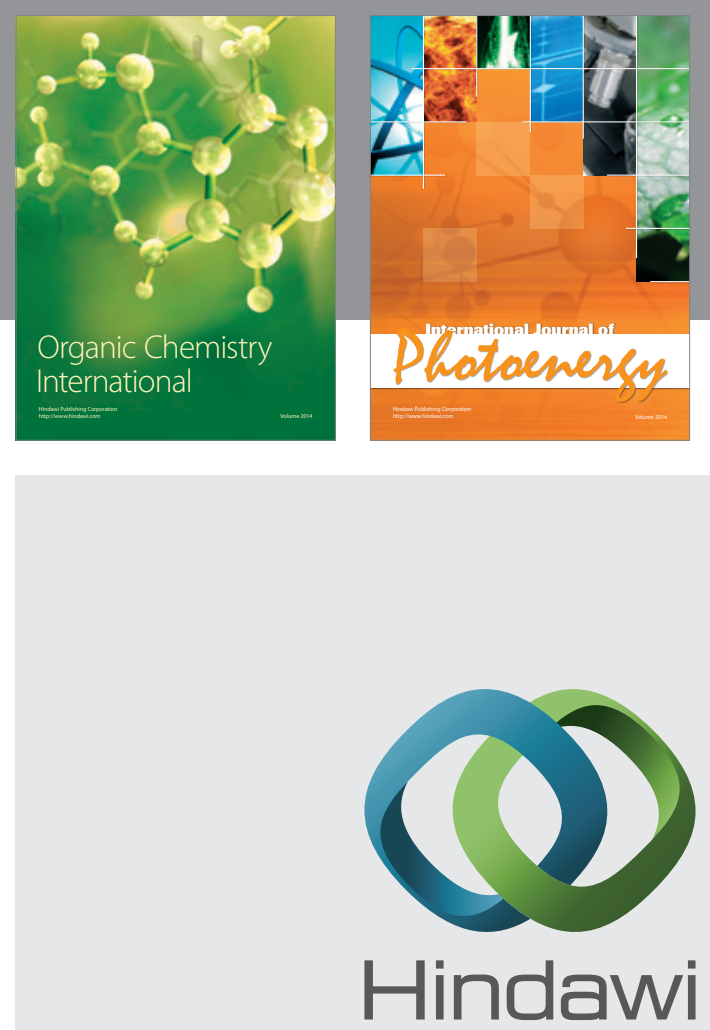

Submit your manuscripts at

http://www.hindawi.com
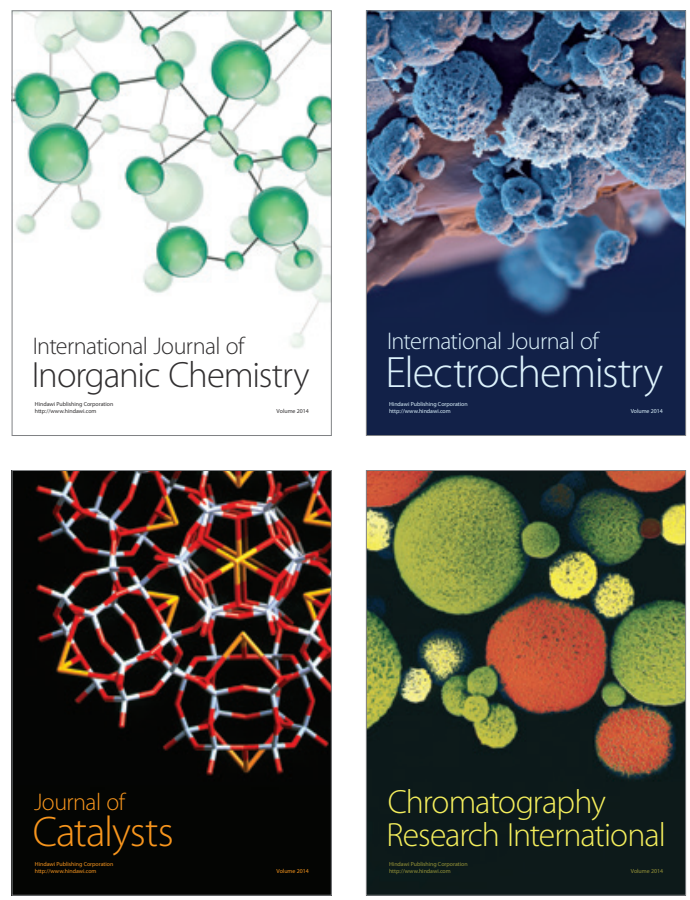
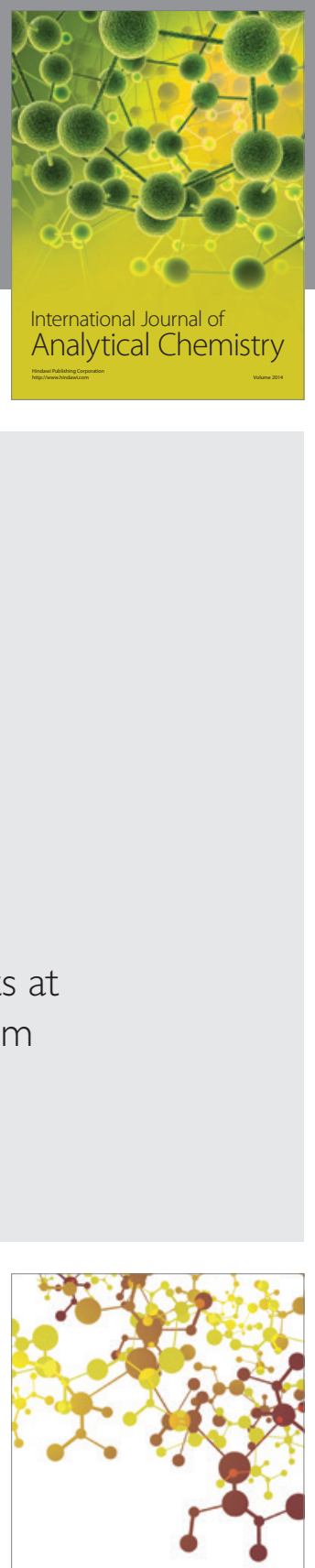

Journal of

Applied Chemistry
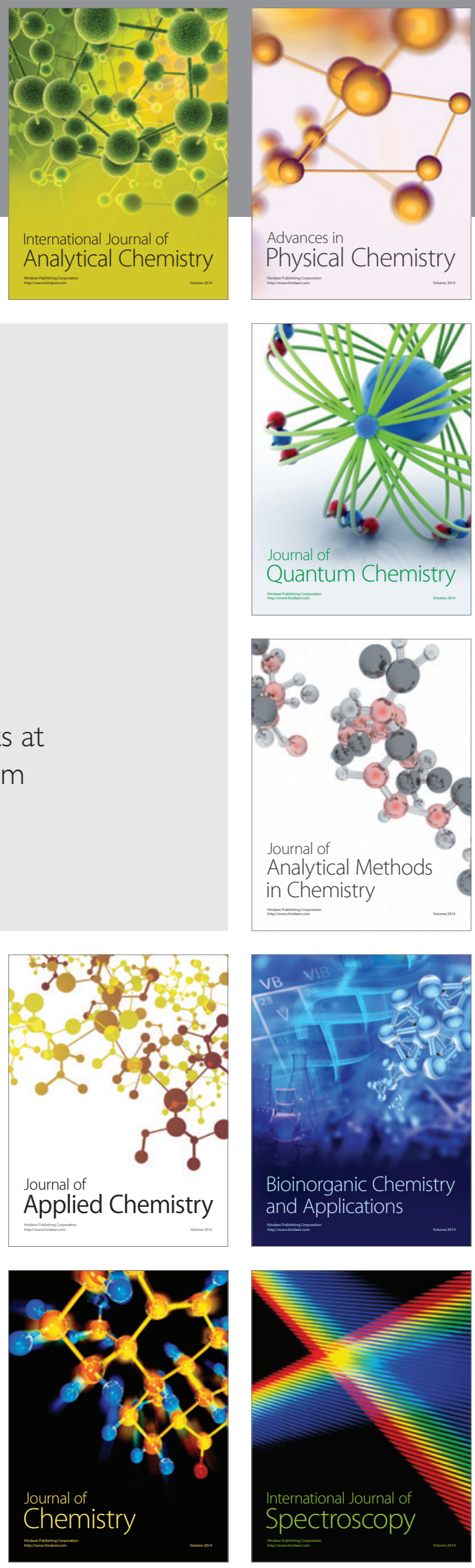